\title{
MARKERS FOR INFLAMMATION AND OXIDATIVE STRESS IN PATIENTS WITH CORONARY ARTERY DISEASE AND MICROVASCULAR DISEASE - IS THERE A DIFFERENCE?
}

\author{
Z. Cherneva', R. Cherneva², E. Manov³, N. Runev³ \\ 1 University Hospital of the Ministry of Internal Affairs - Sofia, Bulgaria \\ ¿University Hospital for Respiratory Diseases "Sv. Sophia" - Sofia, Bulgaria \\ ${ }^{3}$ Department of Propaedeutics of Internal Medicine, Clinic of Cardiology, Medical University - Sofia, Bulgaria
}

\begin{abstract}
Introduction: The clinical significance of inflammation (and markers such as resistin, hsCRP) and oxidative stress (e.g. 8-isoprostanes) for microvascular disease (MVD) and coronary artery disease (CAD) is still elusive. Aims: To determine the role of the markers for inflammation and oxidative stress as independent markers for MVD. Methods: Ninety consecutive patients were recruited: twenty-five of them had CAD; thirty - MVD and thirty-five were controls. The latter included patients with atypical chest pain, risk factors, lack of coronary artery disease and negative adenosine test. Coronary angiography was performed in all participants. The adenosine test was performed in those without $C A D$, hs CRP, resistin in plasma and urine 8-isoprostanes were measured. The correlation of all these indicators with CAD and MVD was analyzed. Results: The 8-isoprostanes showed significant differences between patients with MVD and CAD $(0,055 / 0,52 \mathrm{pg} / \mathrm{mmol}$ Cre; $p=0,028)$. The same trend was found between CAD patients and the control group $(0,055 / 0,003 \mathrm{pg} / \mathrm{mmol} \mathrm{Cre} ; \mathrm{p}=0,041)$; as well as between those with MVD and the control group $(0,52 / 0,003 \mathrm{pg} / \mathrm{mmol} \mathrm{Cre} ; p=0,001)$. The highest values of 8-isoprostanes were detected in patients with MVD - 0,52 pg/mmol Cre. Markers for inflammation were similar in patients with MVD and CAD (hsCRP- $p=0,091$; resistin $-p=0,32$ ). Conclusions: $h s$ $C R P$, resistin and 8-isoprostanes are involved in the pathogenesis of both CAD and MVD. However, oxidative stress is probably more important for MVD, therefore 8-isoprostanes can be a part of panel of markers for its detection and analysis.
\end{abstract}

Key words: inflammation, oxidative stress, microvascular disease, coronary artery disease

Corresponding author: Zheina Vlaeva Cherneva, University Hospital of the Ministry of Internal Affairs, General Skobelev Blvd., Sofia, Bulgaria, tel.: +359 88956977, e-mail: jenicherneva@yahoo.com

\section{INTRODUCTION}

T he basic impairment in the pathogenesis of MVD is reduced coronary reserve in the absence of CAD. There are different hypotheses about the etiology of MVD. Impaired autonomous regulation, increased perception of pain, endothelial dysfunction, increased inflammatory mediators, hypercoagulative status, hypercontractility of the smooth muscle cells that are located closely to a non-obstructive plaque or hormone disbalance are often implicated. Inflammation and oxidative stress have been recently accepted as the key pathophysiological mechanisms of MVD. Thus measuring the markers of oxidative stress (such as urine 8-isoprostanes) and inflammation (e.g. plasma concentration of hsCRP and resistin) in patients 
with MVD and their comparison to those with CAD could clarify their role as additional and/or independent diagnostic markers for MVD [1-7].

The aim of our study was to determine the role of the markers for inflammation and oxidative stress as independent markers for MVD.

\section{MATERIAL}

The study included ninety patients: 25 with OCAD, 30 with MVD and 35 patients served as controls. Coronary angiography was performed in all patients. The control group included patients with cardiovascular risk factors, atypical chest pain, lack of CAD and negative adenosine test. Exclusion criteria were: known ischaemic heart disease, BMI $>30 \mathrm{~kg} / \mathrm{m}^{2}$, chronic pulmonary disease, respiratory failure, obstructive sleep apnea, known diabetes mellitus, chronic kidney disease, known neoplastic disease, autoimmune disease or immune-suppressive therapy. Five milliliters of blood and three milliliters of a morning urine sample were collected from all the patients. A signed informed consent was preliminary delivered from all of them.

\section{METHODS}

Medical history was collected and physical examination was performed. Anthropometric indices including height, weight, BMI, waist circumference were measured. Laboratory and instrumental methods (ECG, echocardiography, coronarography, intravascular ultrasound) were applied. All the patients underwent coronary angiography by Phillips Allura X per FP 20 in the invasive laboratory of the University Hospital "Alexandrovska" during the period Jan-Sep., 2015 year [1, 2].

Coronary flow measurement was used to determine the coronary artery reserve. A coronary artery obstruction was excluded. Microvascular disease was assumed if the coronary artery supply increased less than 2.5 fold after a maximal hyperemic stimulus (adenosine). $[2,3]$. The urine concentration of 8-isoprostanes was measured by mass spectrometry, using a kit for 8-isoproatnes (Cayman, Chemical USA). The concentrations were given in $\mathrm{pg} / \mathrm{mmol}$ creatinine. Plasma levels of resistin were measured, applying sandwich ELISA, RayBio_Human ResistinCat\#:ELH-Resistin-001 kit. The concentration of resistin was presented in pg/ $\mathrm{ml}$. hsCRP was determined by immunonephelometry. Concentrations were presented in $\mathrm{mg} / \mathrm{l}$.

The statistical analysis was performed on a SPSS 15.0 package. $P<0.05$ was assumed as statistically significant. The distributive test of Kolmogorov Smirnov showed the absence of normal distribution in the three groups of patients (controls, patients with $C A D$ and
MVD). A descriptive statistics for the markers of inflammation (hsCRP, resistin) and oxidative stress (8-isoprostanes) was applied. All the markers were presented by medians \pm standard deviation. For the comparison between the three groups of patients non-parametric methods (Kruskall-Wallis, Spearman's rank test) were used.

\section{RESULTS}

Table 1 demonstrates the medians of the inflammatory markers (hsCRP and resistin) in the three groups of patients.

Table 1. Comparative analysis of the plasma levels of hsCRP and resistin between the three groups of patients (coronary artery disease patients, microvascular disease, controls)

\begin{tabular}{|l|r|r|}
\hline \multicolumn{1}{|c|}{ Patients } & \multicolumn{1}{|c|}{$\begin{array}{c}\text { Medians } \\
\text { of hsCRP, } \mathrm{mg} / \mathrm{l}\end{array}$} & $\begin{array}{c}\text { Medians } \\
\text { of resistin, } \mathrm{pg} / \mathrm{ml}\end{array}$ \\
\hline $\begin{array}{l}\text { Coronary artery disease/ } \\
\text { The control group }\end{array}$ & $\begin{array}{r}\mathbf{2 , 1 6 / 1 , 4} \\
\mathrm{p}=0,037\end{array}$ & $\begin{array}{r}\mathbf{2 0 7 6 / 6 2 5} \\
\mathrm{p}=0,023\end{array}$ \\
\hline $\begin{array}{l}\text { Microvascular disease } \\
\text { /The control group }\end{array}$ & $\mathbf{3 / 1 , 4}$ & $\mathbf{2 1 1 0 / 6 2 5}$ \\
\hline Coronary artery dise- & $\mathrm{p}=0,001$ & $\mathrm{p}=0,001$ \\
ase/ Microvascular & $\mathbf{2 , 1 6 / 3}$ & $\mathbf{2 0 7 6 / 2 1 1 0}$ \\
disease & $p=0,91$ & $p=0,32$ \\
\hline
\end{tabular}

A statistically significant difference in hs-CRP levels existed between the patients with MVD and the controls and between the patients with CAD and the controls. hsCRP levels were comparable between the patients with CAD and those with MVD. The data were similar, regarding resistin plasma levels. Its values were significantly higher in patients with CAD and MVD, when compared to controls. No difference existed in resistin plasma levels between CAD and MVD patients.

The medians of urine 8-isoprostanes in patients with CAD, MVD and controls are presented in Table 2. The medians of 8-isoprostanes in patients with microvascular disease were statistically higher in comparison to those with coronary artery disease. Both values were significantly higher in comparison to controls (Table 2).

Table 2. Comparative analysis of the urine concentrations of 8-isoprostanes between the three groups of patients (with coronary artery disease, microvascular disease and controls)

\begin{tabular}{|c|c|c|c|}
\hline Patients & $\begin{array}{c}\text { Coronary ar- } \\
\text { tery diseasel } \\
\text { The control } \\
\text { group }\end{array}$ & $\begin{array}{c}\text { Microvascu- } \\
\text { lar disease/ } \\
\text { The control } \\
\text { group }\end{array}$ & $\begin{array}{c}\text { Coronary } \\
\text { artery disease } \\
\text { / Microvascular } \\
\text { disease }\end{array}$ \\
\hline 8-isoprostanes, \\
pg/mmol Cre & $0,055 / 0,003$ & $0,52 / 0,003$ & $0,055 / 0,52$ \\
\cline { 2 - 4 } & $p=0,041$ & $p=0,001$ & $p=0,028$ \\
\hline
\end{tabular}




\section{DISCUSSION}

Isoprostanes are markers for lipid peroxidation being stable and sensitive indicators for oxidative stress in vivo [4]. Their increased urine excretion is associated with cardiovascular pathology, obesity, diabetes mellitus, insulin resistance, endothelial dysfunction, coronary remodeling and atherosclerosis [5-7]. Our results confirm recent data. They show that 8-isoprostanes are increased in CAD and MVD compared to controls. The role of oxidative stress in the development of MVD is still elusive and the evaluation of urine concentration of 8-isoprostanes in patients with MVD may elucidate this. 8-isoporostanes are statistically different in the three groups of patients reaching highest values in MVD group. Hence, oxidative stress is probably more important for the pathogenesis of MVD and isoprostanes could be included in its diagnostic panel.

We have found that hsCRP is significantly increased in patients with CAD and MVD in comparison to controls. However, there is not a significant difference, between the groups of patients with CAD and MVD. Our results confirm that hsCRP is a non-specific marker typical for inflammation and atherosclerosis. On the other hand, it is a modulator of many processes that can contribute to the progression of atherosclerosis by oxidative stress. Its unfavorable effects upon endothelial and smooth muscle cells could potentiate the endothelial dysfunction as well as atherothrombosis [8-12].

Similar results were obtained for resistin. CAD and MVD patients have shown higher resistin values in comparison to controls. This supports recently published data, which showed that the increased resistin is associated with higher prevalence of cardiovascular events. It plays a key role in the low-grade inflammation and progression of atherosclerosis [13, 14]. Increased resistin levels are found in patients with hypertension and albuminuria, regardless of other risk factors. Thus, it is related to microvascular dysfunction in the early stages of essential hypertension [15, 16]. A significant difference in resistin plasma levels between CAD and MVD has been established. It may be assumed that resistin should not be applied as independent inflammatory marker in the pathogenesis of both diseases. In contrast to others, we have not found a link between resistin and angiographically established severity of the coronary disease [17].

\section{CONCLUSIONS}

Inflammation and oxidative stress play an important role in the pathogenesis and the clinical outcome of patients with CAD. There are a few studies regarding this issue in MVD. We have established that hsCRP, resistin and 8-isoprostanes participate in the pathogenesis of both MVD and CAD. Oxidative stress seems to be more important for the development of MVD. 8-isoprostanes could be a part of the MVD diagnostic panel, as well as a marker for therapeutical follow-up.

Acknowledgements: None to be declared.

Conflict of interests: All the authors state no conflict of interests.

\section{REFERENCES}

1. Runev N, Manov E. Diastolic left ventricular dysfunction - invasive assessment. 1st edition Maurice-France; LAP LAMBERT Academic Publishing 2014.

2. Jasmin Č. Procedural Techniques of Coronary Angiography. Advances in the diagnosis of Coronary Atherosclerosis 2011;6: 95-121.

3. Hector M, Gogas B, Serruys P, et al. IVUS-based imaging modalities for tissue characterization: similarities and differences. Int J Cardiovasc Imaging 2011;21:215-224.

4. Davi G, Guagnano M, Ciabattoni G, et al. Platelet activation in obese women: role of inflammation and oxidant stress. JAMA 2002;288:2008-2014.

5. Davi G, Ciabattoni G, Consoli M, et al. In vivo formation of 8-iso-prostaglandin f2alpha and platelet activation in diabetes mellitus: effects of improved metabolic control and vitamin $\mathrm{E}$ supplementation. Circulation 1999;99:224-229.

6. Minuz $P$, Patrignani $P$, Gaino $S$, et al. Increased oxidative stress and platelet activation in patients with hypertension and renovascular disease. Circulation 2002;106:2800-2805.

7. Lavie L, Lavie P. Molecular mechanisms of cardioavascular disease in OSAHS: The oxidative stress link. European Resp J.2009;33:1467-1484.

8. Higashi $\mathrm{Y}$, Noma K, Yoshizumi M, et al. Endothelial function and oxidative stress in cardiovascular diseases. Circ J.2009;73:411-418.

9. Wu J, Stevenson M, Brown J, et al. C-reactive protein enhances tissue factor expression by vascular smooth muscle cells: mechanisms and in vivo significance. Arterioscler Thromb Vasc Biol. 2008;28:698-704.

10. Witteles R, Fowler M. Insulin-resistant cardiomyopathy clinical evidence, mechanisms, and treatment options. J Am Coll Cardiol 2008;51:93-102.

11. Bassuk S, Rifai N, Ridker P. High sensitive C-reactive protein: clinical importance. Curr. Probl. Cardiol 2004;29:439-493.

12. Tomai F, Ribichini F, Ghini A, et al. Elevated C-reactive protein levels and coronary microvascular dysfunction in patients with coronary artery disease. European Heart Journal 2005;26:2099-2105.

13. Libby $P$, Crea F. Clinical implications of inflammation for cardiovascular primary prevention. European Heart Journal 2010;31:777-783.

14. Gencer B, Auer R, Rekeneire N, et al. Association between resistin levels and cardiovascular disease events in older adults: The health, aging and body composition study. Atherosclerosis 2016;245:181-186.

15. Reilly $M$, Lehrke $M$, Wolfe $M$, et al. Resistin is an inflammatory marker of atherosclerosis in humans. Circulation 2005;111:932-939.

16. Tsioufis C, Dimitriadis K, Selima M, et al. Association of resistin with urinary albumin excretion in nondiabetic patients with essential hypertension. Am J Hypertens 2010; 23(6),681-686.

17. Sinan U, Canbolat I, Baydar O, et al. Relationship between increased serum resistin level and severity of coronary artery disease. Angiology 2014; 65:239-242.

Received: February, 2019

Revised: March, 2019 - Accepted: April, 2019 